\title{
Artelogie
}

Recherche sur les arts, le patrimoine et la littérature de l'Amérique latine

17 | 2021

Transformaciones en Cuba contemporánea: cultura y sociedad

\section{Bartender (Notas sobre una enjundia teatral)}

Laura Ruiz Montes

\section{(2) OpenEdition}

Journals

Edición electrónica

URL: https://journals.openedition.org/artelogie/9835

DOI: 10.4000/artelogie.9835

ISSN: 2115-6395

Editor

Association ESCAL

Referencia electrónica

Laura Ruiz Montes, «Bartender (Notas sobre una enjundia teatral)», Artelogie [En línea], 17 | 2021,

Publicado el 27 septiembre 2021, consultado el 15 septiembre 2022. URL: http://

journals.openedition.org/artelogie/9835 ; DOI: https://doi.org/10.4000/artelogie.9835

Este documento fue generado automáticamente el 15 septiembre 2022

All rights reserved 


\title{
Bartender (Notas sobre una enjundia teatral)
}

\author{
Laura Ruiz Montes
}

La espera para comprar una tarjeta que permita una conexión por Wi-fi es el pórtico del cuento «Bartender»" ganador del Premio La Gaceta de Cuba en su última edición. Su autor, Pedro Franco, es un actor y director teatral, devenido narrador. Los andares de Franco por bares, cafés y cabarets se remontan a la puesta en escena de la obra «Café $\mathrm{CCPC}{ }^{4}$, que el grupo cubano de teatro El Portazo, bajo su dirección artística, estrenara en el ya no tan cercano año 2015. Si entonces el ready-made dramatúrgico apoyado en la estética del cabaret tuvo un importante éxito de crítica y de asistencia de público ahora, con «Bartender» y más experiencia, su autor vuelve cruzar la línea frágil que existe entre el espacio público y el privado en eso que hemos dado en llamar «realidad nacional» y que hace pensar que subyacente está ese otro estanco que vendría a ser la «irrealidad nacional». Si en la obra de teatro "Café CCPC», Pedro Franco intentaba narrar a lo grande, con total acierto y en ritmo Minelli, nuestra épica y lírica isleña, en «Bartender», el joven escritor parece circunscribirse a un espacio más pequeño y reducido, al menos en apariencia.

2 La barra de un hotel de provincia es el centro de atención del relato de marras. Pero no se trata de la barra de cualquier hotel, sino de la única barra del único hotel de una ciudad de provincia donde, con suerte, computadora, celular, tablet, o lo que sea, se podría acceder a Internet, vía Wi-fi, por el nunca módico precio de casi medio salario por una hora ${ }^{5}$. Pudiera parecer que la descripción, magistralmente sintética, que hace el narrador en los párrafos iniciales sobre la relación individuo/prosperidad inundará las páginas del cuento pero esto, al decir de los franceses, es solo un truc. El autor no dedica a este calvario económico más que el tiempo necesario. Casi de inmediato se centra en un presente otro donde dos hombres conversan, mientras transcurre la noche. No hay que olvidar que «CCPC» también se centraba en un presente pero era un 
hoy acumulativo que reunía en sí siglos de historia nacional: contenido/contenedor, una especie de termo de donde brotaban guerreros, arrumacos políticos, desgarros emocionales y revisitaciones patrióticas, con una estética de cabaret político muy bien estructurada.

3 La conversación entre el bartender y el artista que quiere lograr su conexión a Internet, y cuya espera de la posible tarjeta tarda horas va, en el cuento premiado, de lo particular a lo general en un viaje de ida y vuelta. El tiempo que demora la carpetera en buscar la consabida tarjeta, se convierte, sin más, en EL TIEMPO: narrativo, hipotético, pero a la vez real. En él, las frases se confunden y camarero y escritor se interrumpen para escarbarse y contarse uno al otro los tropiezos y vaivenes de sus existencias.

4 La relectura de la relación épica y decimonónica del general mambí Antonio Maceo con el militar español Arsenio Martínez Campos, presente en la obra teatral ya enunciada, deviene, en el cuento que nos ocupa, paradigma de incomunicación entre dos hombres en lados opuestos del mismo campo de batalla. La ambigüedad del discurso de la manigua, enunciado en "CCPC», sus «entonces no nos entendemos», se repite en la narración del cuento premiado cuando, barra de por medio, servidor y servido ponen sus cartas sobre la mesa. Una única cerveza dura toda la noche pasando de la máxima frialdad al calor insoportable, hasta llegar al atragantamiento cicuta. De esa misma manera el protagonista de «Bartender»-que a todas luces es el alter ego de Pedro Franco-, también «traga sus buches amargos» cuando el camarero, macho, cultivador de tríceps y bíceps, insiste en preguntar si es verdad que en aquella representación teatral había algo a lo que llamaban «karaoke azucarero» y «transformismo militante».

Como el héroe de «Bartender» no tiene nombre, llamémosle Franco, como su autor; no Pedro, para no parecer apostólicos y no tener que convivir con una necesaria relectura de la religión como compensador ilusorio y el opio y los pueblos... Eso podría quedarse para otra ocasión. Ahora solo sería interesante observar como desde una barra de hotel (un no lugar más donde casi nadie es lo que dice ser, o lo es pero con más alcohol en venas que hace que al final nada es lo que sea, o lo sea pero puede que no lo vuelva a ser después...) se hace un análisis en perspectiva, intertextualidad incluida, de la antigua y movilizadora enjundia teatral para generar -cuento y obra de teatro- una extraña, coyuntural e idealista «zona de contacto». Camarero y artista se convierten, además de en personajes de la narración, también en una especie de autor y crítico literario. En una suerte de performance narrativo, Pedro Franco, autor, habla a través de sus personajes para defender, enjuiciar, burlarse y aplaudir aquella, su propia obra, en un acto totalmente carnavalesco. Un baile intelectual de disfraces muy bien pensado.

De este modo, el artista/comprador de tarjeta Wi-Fi, para explicar al camarero que la lógica de la puesta estuvo signada por la mímesis, le comenta cuáles fueron los recursos empleados, en un ejercicio revelador de intenciones y «técnicas». Así, el personaje utiliza ejemplos básicos:

7 Si enciendes la televisión y ves una frase de un discurso o un escrito político totalmente fuera de su habitat natural ${ }^{6}$ ipor qué no podríamos retomar otros textos que podrían ser poemas, fragmentos de obras de teatro, letras de canciones cursis y enrollarlos dentro de la misma hoja de tamal de nuestro anecdotario nacional? ¿Dónde está la receta? ¿En el fondo de qué caja de los abuelos se quedó el libro de apuntes que decía qué va con qué, cuánta pizca de esto o de lo otro? ¿Dónde está la receta, dónde la caja, dónde el libro, dónde los abuelos? (Franco, 194) 
«Gusanos cerebrales», le explica Franco personaje al camarero. «Tú inventaste eso», replica el otro. «No lo inventé, lo dijo Oliver Sacks», devuelve el primero, para añadir sin freno y ampulosamente: «Definidos como la activación repetitiva y autónoma de frases musicales, esos gusanos cerebrales pueden durar días, incluso semanas.... ${ }^{7}$.

Lo que va pasando por la imaginación del camarero/biólogo marino, mientras el artista habla de gusanos cerebrales hubiera podido ser representado como un nauseabundo capítulo de alguna serie escatológica de aquellas que era posible encontrar en lo que entonces llamaban «el paquete»" ${ }^{8}$, pero esto solo lo sabe Franco autor, que coquetea con este fenómeno, aun sin nombrarlo. Franco protagonista, en cambio, insiste en decodificar el valor semántico del transformismo militante en aquel, su «Café CCPC», que presentaba a un transformista de muy ceñido traje, diseñado a partir de una bandera cubana, cantando «Te solté la rienda», mientras blandía, una hoz y un martillo. Lo que fue y nunca más será aparece contextualizado en el gusano cerebral que Franco entona, una y otra vez, mientras piensa en lo poco elegante del término «desmerengamiento» del campo socialista, en el ya extinto programa televisivo «9550» (que remitía a la cantidad de kilómetros que separaba La Habana de Moscú), en sí mismo como una matrioshka ahora huérfano de otras matrioshkas, en la utilidad de la virtud y para qué mentir: en sí.

10 Franco personaje canta recostado a la barra, canta y mueve sus propias manos segando con la hoz de su mano izquierda, golpeando con el martillo de su diestra. A ratos es la cantante, a ratos el transformista de «CCPC» y a ratos es Cuba. Cuba que deja ir. Cuba que se suelta. Cuba que a ratos está muy sola... Y a eso sí se refiere el autor de «Bartender» cuando hace una especie de paneo de cámara y con enunciados breves y lúdicos remite a las relaciones Cuba/España; Cuba/Usa; Cuba/URSS, para acabar repitiendo, en exquisita intertextualidad frases ya anteriormente escuchadas en «Café CCPC». De esta manera, el grito de no confundir Caracas con Moscú no es aquí una simple lección de geografía.

11 Me permito citar in extenso la canción/gusano cerebral que tortura al personaje, como ejemplo de la eficacia de lo que extraído de su contexto/habitat natural y depositado en otras coordenadas -y con otras intenciones- es capaz de crear un semioculto pero eficaz discurso.

12 Se me acabó la fuerza de mi mano izquierda. Voy a dejarte el mundo para ti solito. Como al caballo blanco le solté las riendas, a ti también te suelto y te me vas ahorita. Y cuando al fin comprendas que el amor bonito lo tenias conmigo, vas a extrañar mis besos en los propios brazos de la que esté contigo. Vas a sentir que lloras sin poder siquiera derramar tu llanto. $Y$ has de querer mirarte en mis ojos negros que quisiste tanto, que quisiste tanto, que quisiste tanto. Cuando se quiere a fuerza rebasar la meta y se abandona todo lo que se ha tenido, como tú traes el alma con las riendas sueltas ya crees que el mundo es tuyo y hasta me das tu olvido. Y cuando al fin comprendas que el amor bonito lo tenias conmigo, vas a extrañar mis besos en los propios brazos de la que esté contigo... (Franco 196)

«Globalización», le interrumpe a gritos el bartender. A lo que Franco personaje, ofendido, responde «iNOO!, Yúdice y los procesos estratificados de la cultura», para soportar que el camarero diga que recuerda perfectamente a la española Rocío Jurado cantando esa canción y que tenía tremendas tetas; que entre ellas se colocaba a veces el micrófono. Pero la lucha de contrarios siempre presente en este cuento no se hace esperar. Servido se enfrenta a servidor y le habla de cómo en «CCPC» cada canción, 
cada gesto, cada pachanga -política o no- se resiste a ser pasado muerto. Le explica, al filo de las dos de la madrugada, cuando ya los lectores anticipamos que la tarjeta para el Wi-Fi no va a aparecer, la diferencia entre promesas y promesas no cumplidas... «Sí, como las llamadas telefónicas en espera», sostiene el camarero, llevando a la terrenalidad, aterrizando, la disertación político-filosófica del otro.

Una vez más no hay remedio para la incomunicación entre servidor y servido, como jamás la hubo entre el general Maceo y el español Martínez Campos y por ello, el lector no es capaz de aventurar el final que el cuento habrá de tener. El discurso del narrador, a partir de la pregunta sobre qué es el amor a la patria, que coloca per se la sabrosura y el llanto, la asfixia, la perpetuidad, los antiguos centrales azucareros desaparecidos o el país en fuga en la misma copa de cerveza caliente que queda sobre la barra, no es EL FINAL del cuento, ni siquiera es UN FINAL. Es simple y llanamente lo que debe haber inclinado la balanza para que premiaran «Bartender», esta historia que reiteradamente remite al lector a una obra de teatro concebida y puesta en escena tiempo atrás que complementaría y conduciría a su vez a la (re)lectura de una poética, símbolo de la teoría del todo, que mezcla ficción y realidad. Es hacer cuanto se pueda con lo que se tiene: ripios de narración, intertextualidad con el teatro cubano contemporáneo, referencias cruzadas con la historia nacional, etc.

No ha de resultar extraño entonces que meses después del momento en que se desarrolla esta trama -y hasta hoy- en el mismo parque donde está enclavado el hotel/ locación del cuento de Franco, a cualquier hora, muchas personas accedan a un nuevo y muy localizado servicio de Wi-Fi, por un poco menos de costo económico. ¿Profecía? ¿Un deja vu más entre literatura y sociedad? ¿Dónde acaba el arte y dónde comienza la realidad? ¿Dónde la ficción y dónde los escenarios verdaderos? Quizás solo se trata de una gran pericia en la manera de narrar a partir del borramiento de toda frontera.

«Esto es lo que hay», se despiden en el cuento laureado el bartender y el artista, al filo del amanecer, cuando las sombras dejan de ser literatura, las ojeras pierden encanto y los pájaros atraviesan en dirección contraria el camino antes hecho: la ruta trazada, de una punta a otra de la plazuela pequeña, aldeana, que va a seguir llamándose «Parque de la Libertad». Allí donde está la estatua de José Martí junto a la señora de las cadenas rotas y los senos magníficos, regios, desprejuiciadamente erguidos al aire?

\section{NOTAS}

1. Pedro Franco, «Bartender», en Maneras de narrar. Cuentos del Premio La Gaceta de Cuba (2020-2030). Compilación y prólogo de Boris Badía, Ediciones Unión, La Habana, 2031. Págs 193-197. Todas las citas son de esta edición.

2. «Café CCPC» [Cuban Coffee by Portazo's Cooperative]

3. Pedro Franco, «Bartender», en Maneras de narrar. Cuentos del Premio La Gaceta de Cuba (2020-2030). Compilación y prólogo de Boris Badía, Ediciones Unión, La Habana, 2031. Págs 193-197. Todas las citas son de esta edición. 
4. «Café CCPC» [Cuban Coffee by Portazo's Cooperative]

5. Es válido aclarar que este cuento de Franco, como su obra de teatro, también está ambientado en 2015, cuando aún era punto menos que inaccesible el acceso al servicio de Wi-Fi en Cuba.

6. Es importante señalar aquí que el camarero terminó su carrera de biólogo marino pero por razones que no tiene sentido argumentar relacionadas con la bolsa, wall street, el alza de los precios, la baja de los pesos, etc, trabaja ahora en este bar, por lo que el término habitat le resulta completamente natural.

7. Eduardo Chirino, «Para llegar a Missoula», en Poéticas de los dislocamientos. (Gisela Heffes ed.), Colección dislocados, Literal Publishing, Houston Texas, 2012. Pág. 149, citado por Pedro Franco en su «Bartender», ob. cit. p. 196.

8. «Paquete»: Fenómeno de difusión que trajo aparejado numerosas polémicas en diferentes medios culturales. Ver en la red los espacios dedicados a esta opción, publicados en los blogs y revistas: cine cubano: la pupila insomne, oncubamagazine.com, www.cubanet.org, www.cibercuba.com y muchos otros. Y que Diario de Cuba llamó, con doloroso sarcasmo, «la televisión satelital de los pobres», en www.diariodecuba.com. Contando la televisión cubana entonces con cinco canales de televisión y algunas horas de transmisión de los llamados «Tele-centros» que existían en no todas las provincias del país, algunos «trabajadores por cuenta propia» ejercían el oficio de «paqueteros». Con antenas parabólicas o con un servicio pirata de Internet accedían a series televisivas, películas, documentales y una variada programación que no se trasmitía por los canales tradicionales pero que creaban, a quien pudiera pagarlos la ilusión de tener en casa algo semejante a la televisión por cable.

9. Texto aparecido en la Revista Matanzas. Año XVI. No. 3. Septiembre-diciembre, 2015. Matanzas, Cuba.

\section{RESÚMENES}

La espera para comprar una tarjeta que permita una conexión por Wi-fi es el pórtico del cuento «Bartender» ${ }^{1}$ ganador del Premio La Gaceta de Cuba en su última edición. Su autor, Pedro Franco, es un actor y director teatral, devenido narrador. Los andares de Franco por bares, cafés y cabarets se remontan a la puesta en escena de la obra "Café $C C P C »^{2}$, que el grupo cubano de teatro El Portazo, bajo su dirección artística, estrenara en el ya no tan cercano año 2015. Si entonces el ready-made dramatúrgico apoyado en la estética del cabaret tuvo un importante éxito de crítica y de asistencia de público ahora, con «Bartender» y más experiencia, su autor vuelve cruzar la línea frágil que existe entre el espacio público y el privado en eso que hemos dado en llamar «realidad nacional» y que hace pensar que subyacente está ese otro estanco que vendría a ser la «irrealidad nacional».

\section{ÍNDICE}

Palabras claves: Cuento Cubano Contemporáneo, Bartender, Teatro, Pedro Franco 


\section{AUTOR}

\section{LAURA RUIZ MONTES}

Poeta y editora cubana. Autora de una reconocida obra lírica, ha escrito también teatro, narrativa para niños y crítica de arte. Durante más de dos décadas ha desarrollado, igualmente, un encomiable trabajo editorial. lruizmontes66@gmail.com 